\title{
OS PARADIGMAS \\ DA MODERNIZAÇÃO DO ESTADO DO CEARÁ \\ E o Processo de Construção \\ DA BARRAGEM DO CASTANHÃO
}

Francisca Silvania De Sousa Monte

R E S U M O Este trabalho resulta de pesquisa para tese de doutorado cujo objetivo foi investigar em que medida o processo de uso e controle das águas no Ceará, tendo como base a Barragem do Castanhão, contribuiu para levar o estado a se transformar em paradigma da modernização, principalmente a modernização hidrica. Foram realizadas entrevistas com políticos, agentes governamentais, organizaçōes da sociedade civil e outros agentes relevantes no processo. Foram também consultados documentos e relatórios de várias instituiçôes envolvidas na implantação da Barragem. Concluiu-se que a modernidade hidrica está desenhando uma nova configuração territorial no estado do Ceará, transformando o espaço geográfico no espaço da racionalidade técnica a serviço de interesses privados, e que o desenvolvimento pretendido com a implantação da Barragem ocasionou um processo de modernização excludente, principalmente dos mais diretamente atingidos pelas obras.

P A L A V R A S - C H A V E Modernização; desenvolvimento; Ceará; barragem; água; exclusão.

\section{A CONSTRUÇÃO DO CEARÁ MODERNO}

Nas duas últimas décadas, o estado do Ceará tem sido apresentado no cenário nordestino e nacional como expressão de transformação na estrutura tradicional de poder. Segundo Barreira (2002), foi sob o signo da ruptura, exemplificado no slogan "governo das mudanças", que um grupo de empresários liderados por Tasso Jereissati ocupou a cena política cearense, projetando o Ceará para o restante do país como um exemplo de Estado moderno.

Diógenes (2002) destaca que tivemos no Ceará, no final dos anos 1980, a produção de novas imagens políticas que se estabeleceram no cenário local, baseadas na oposição e legitimação diante das chamadas oligarquias coronelísticas. A construção de um Ceará moderno teve por base uma retórica das mudanças, com o governo estadual assumindo compromissos:

[...] com a superação de valores deformados, que colocavam o interesse de pequenos grupos acima dos interesses maiores da sociedade. Compromisso com o combate a todas as formas de clientelismo. Compromisso com a recuperação da moralidade do serviço público, onde o Estado deve ser visto como instrumento para a realização do bem comum e não para o serviço das oligarquias. Compromisso com o combate à miséria e o respeito à cidadania como direito inalienável de todos os homens e mulheres do Ceará. (Ceará, 1987, p.8) 
1 Este discurso foi utilizado na campanha de Maria Luíza Fontenelle à prefeitura de Fortaleza em 1985 (Barreira, 1993, 2002) e também em campanhas para a Assembléia Legislativa no final da década de 1970 por candidatos de esquerda (Lemenhe, 1998).
O discurso de ataque aos "coronéis" e ao "coronelismo" já havia sido anunciado anteriormente, ${ }^{1}$ mas, pela primeira vez, de acordo com Barreira (op.cit.), tornara-se elemento fundamental da estratégia que deu suporte ao surgimento de novos atores políticos. De acordo com a autora, a evocação às mudanças pôs em destaque um capital político e simbólico que toma a forma de regras e legitimação de competências diferentes das até então existentes, de maneira que a herança partidária e laços de fidelidade foram substituídos por critérios que destacavam e priorizavam a formação intelectual e a experiência administrativa.

Para Abu-El-Haj (1997), a mudança política acontecida no Estado teve esta peculiaridade devido à existência de uma herança política tradicional, com muita freqüência tachada de coronelista; foi este tom anticoronelista que assinalou o "marketing político" do candidato Tasso Jereissati ao governo do Estado nas eleições de 1986, facilitado pelas patentes militares de "coronéis" de seus opositores políticos. Pode-se depreender isto da observação feita a seguir:

O tema das mudanças polarizou-se basicamente na promessa de transplante da racionalidade do moderno empresariado nordestino para o plano politico administrativo, erradicando o clientelismo político e substituindo-o pela utilização asséptica e eficiente dos recursos públicos. A imagem ressuscitada nos meios de comunicação de massa foi a do velho e truculento "coronel" defendendo os "currais eleitorais" que as forças modernas se dispunham a romper. (Carvalho, 1987, p.204)

O Ceará passou de estado considerado miserável na imprensa nacional para se tornar exemplo de Estado que deu certo, um modelo a ser seguido ou, para usar uma expressão muito em voga nas manchetes, para ser "uma ilha de prosperidade". Entretanto, para quem quer ir além do discurso e das aparências das estatísticas, Teixeira (1995, p.7) faz perguntas instigantes:

[...] pode-se alegar, como o fazem os dirigentes atuais da coisa pública, do Estado, que todo este processo representa uma ruptura com o passado, com o tempo dos "coronéis"? Até que ponto esta propalada modernização corresponde a uma ruptura real? [...] podem estes dirigentes reclamar a autoria exclusiva dessas transformaçôes como produto de seu jeito de fazer politica, de governar? Há, de fato, uma ruptura com a economia passada, ao ponto de se julgar que o presente não guarda mais nenhuma relação com o passado?

Para Gondim (2002), as mudanças ocorridas na sociedade cearense, a partir da eleição de Tasso Jereissati, aconteceram em função das mudanças estruturais que ocorreram na economia e na sociedade cearense desde a década de 1950, e que criaram as condições para a emergência destas novas elites.

Parente (2000), analisando as elites políticas no estado, defende que estas sempre apresentaram uma fragilidade estrutural causada pela situação de secas freqüentes numa economia fortemente baseada no consórcio gado-algodão. Para o autor, a seca é "um fator importante na decomposição das elites políticas e econômicas cearenses, sobretudo numa situação em que as elites estão despreparadas para enfrentar as intempéries da natureza" (Id., Ibid.,p.58).

Um outro fator desta fragilidade seria a desarticulação destas elites nas regiōes Norte, Sul e Centro do próprio estado, não existindo nem "homogeneidade nem integração espacial" entre elas (Parente, 2002, p. 126). Dizer que estas elites são frágeis politicamente é, para o autor, dizer que "em situação de normalidade, não formam oligarquias fortes 
e permanentes como em Pernambuco, Paraíba e Bahia" (Id., Ibid., loc.cit.). A fraqueza estrutural das elites cearenses revela, a seu ver, "que elas necessitam de maior criatividade para sobreviverem" (Parente, 2000, p.73), e que "a modernização sempre se apresentou como uma estratégia de sobrevivência das elites cearenses" (Parente, 2002, p.126).

Ao mesmo tempo em que tornava frágeis as elites econômicas e políticas, a seca teria tido um papel importante no processo de modernização, uma vez que o seu aparecimento contribuía para a emergência de um quadro técnico e moderno, formado para interferir de forma racional nos seus efeitos (Parente, 2002).

As elites cearenses tinham consciência de que a modernidade ${ }^{2}$ era uma estratégia de sobrevivência política, sem a qual elas não se tornariam independentes dos efeitos climáticos. Essa convicção ter-se-ia evidenciado na década de 1950, com a criação do Banco do Nordeste do Brasil (BNB) e da Superintendência de Desenvolvimento do Nordeste (Sudene), dois órgãos sem os quais não seria possível conceber a eficácia de uma política de modernização conservadora: o BNB sediado em Fortaleza desde 1954, e a Sudene criada em 1959 e sediada em Recife, Pernambuco. "O BNB e a Sudene foram instrumentos importantes na estruturação de um modelo de desenvolvimento regional que tornasse não só a região, mas sobretudo o Estado do Ceará, com mais condições de conviver com as secas" (Parente, Ibid., p.135).

Camilo Calazans de Magalhães, no documento "O desenvolvimento do Nordeste e a ação do BNB", publicado pelo BNB, enfatiza o papel da criação do Banco do Nordeste e da Sudene como "fatos marcantes da fase moderna da história econômica nordestina". Para ele, "é com a entrada do BNB em funcionamento, em 1954, que se inicia esta fase [de modernização], consolidada com a criação da Sudene quase no fim daquela década”. Magalhães destaca que esta fase é marcada por uma nova visão do problema regional, procurando-se a solução dos problemas das disparidades regionais através de uma política de promoção do desenvolvimento, tendo por influência as idéias de desenvolvimento, advindas da Europa e dos Estados Unidos, especialmente as experiências da Tenesse Valley Authority e da Cassa per il Mezzogiorno (Magalhães, 1979, p.13).

Além do BNB e da Sudene, mais três instituições de interesse para o desenvolvimento da região tinham sua área de atuação no Nordeste: o Departamento Nacional de Obras contra as Secas (DNOCS), a Comissão do Vale do São Francisco (CVSF), criada em 1947, e a Companhia Hidroelétrica do São Francisco (CHESF), criada em 1945. A preocupação era fazer com que o BNB e a Sudene cumprissem um papel político e econômico já explicitado pela ideologia desenvolvimentista. "Eram instrumentos ideológicos com objetivos de 'modernizar' também as tradicionais elites da região" (Parente, 2000, p. 135).

Parente (Ibid.) apresenta a tese de que o mergulho do Ceará na ideologia da modernidade se deve a este processo de treinamento e socialização de uma elite técnica e preparada para uma administração racional do estado, sendo o BNB a força difusora da ideologia de modernidade. Para ele, este ambiente propiciou o surgimento de uma elite moderna formada por uma nova geração de empresários. No entanto, argumenta que a passagem de uma mentalidade e de uma prática inscritas no conservadorismo para uma outra de maior racionalidade técnica, identificadas com a modernidade, teve um outro ator destacado: Virgílio Távora, o último governante da "fase dos 'coronéis"” 3 da política cearense.

Virgílio Távora tinha a intenção clara de modificar o perfil econômico do estado. De acordo com Aragão (1998), no final dos anos 1970, a produção algodoeira entrou em profunda crise, da qual até hoje não se recuperou; ao mesmo tempo, Virgílio Távora conseguiu a instalação no Estado do III Pólo Industrial do Nordeste, cedendo incentivos, van2 Pode-se considerar que o
termo modernidade utiliza-
do pelo autor é perpassado
de ambigüidade, uma vez
que o sentido implíito aos
textos é na maioria das ve-
zes, o de modernização, en-
tendida como o desenvolvi-
mento da racionalidade
instrumental, que tem por
base o cálculo custo/benefi-
cio, presente na eficácia, na
produtividade e na competi-
tividade. Esta modernização
foi, em certa medida, alcan-
çada pelas elites políticas
do estado; no entanto, esta
se apresenta muito distante
da modernidade fundamen-
tada na soberania popular e
nos direitos humanos que le-
va à autodeterminação poli-
tica (LECHNER, 1990). Ou-
tras vezes, porém, o termo
se refere à "ideologia de mo-
dernidade" das elites cea-
renses, utilizada nos discur-
sos como indicativo de
ruptura em relação ao pas-
sado.

3 Período compreendido pelos governos de César Cals, Adauto Bezerra e Virgílio Távora, de 1971 a 1982. 
tagens ou mesmo capital aos empresários, assegurado pelo Banco de Desenvolvimento do Ceará (Bandece). Estava desta forma criado o II Distrito Industrial de Fortaleza.

Além do III Pólo Industrial, com a consolidação do II Distrito Industrial de Fortaleza, foram obras do governo de Virgílio Távora: a expansão do apoio à indústria pesqueira e à média indústria; desenvolvimento do pólo têxtil e de vestuário; pólo metal mecânico; expansão da indústria pesqueira; integração da indústria coureira; aproveitamento de novas oportunidades industriais; apoio infra-estrutural; apoio tecnológico e promoção industrial. No setor mineral, foi criada a Companhia Cearense de Mineração (Ceminas) e foi instalado o Centro de Artesanato de Fortaleza (Linhares, 1996). Nesse segundo governo, Virgílio Távora consolidou a transição para a modernidade, que já havia iniciado no seu primeiro governo (Parente, 2002).

Para Parente (2000), a outra condição para desencadear o processo de modernidade nas elites políticas foi a existência de uma tradicional elite homogênea social organizada, reunida no Centro Industrial do Ceará (CIC). O CIC foi fundado em 1919 por um grupo de empresários com o objetivo de tratar de assuntos de interesses comuns aos industriais e estudar possibilidades de novos empreendimentos. Os objetivos da entidade eram voltados, prioritariamente, para os interesses corporativos do setor: suprimento de matéria-prima, comercialização, preços e salários (Matos et al., 1999).

Seu primeiro presidente, Tomás Pompeu de Sousa Brasil, foi também o responsável pela implantação da primeira indústria têxtil do estado do Ceará, no ano de 1881. Esta primeira fase do CIC teve início com um presidente ligado à indústria têxtil, mas 15 anos depois, a presidência passou para os setores salineiro e madeireiro. Este fato esteve ligado à criação de duas organizações: a Federação das Associações de Comércio e Indústria do Ceará (FACIC) em 1928 e o Sindicato das Indústrias Têxteis do Ceará em 1935. Na década de 1940, o CIC foi desativado devido à criação da Federação das Indústrias do Estado do Ceará (FIEC) (Parente, 2000).

Segundo Teixeira (1995), alguns jovens empresários, em 1977, estimulados pela conjuntura de abertura política, começaram a se unir, de forma paralela à FIEC. Havia uma homogeneidade ideológica pelo fato de pertencerem a uma segunda geração de empresários no estado. O então presidente da FIEC, Flávio Costa Lima, percebendo a homogeneidade desse grupo e suas diferenças com os tradicionais empresários, cedeu o espaço do CIC, que estava praticamente desativado desde 1945, para que estes jovens pudessem desenvolver o seu potencial. Era, de acordo com Teixeira (Ibid), o espaço de que eles precisavam para por em prática suas idéias modernizadoras.

Os jovens empresários passaram a pregar uma gestão profissional da administração pública, sem clientelismo, fisiologismo, paternalismo ou corrupção; duras críticas ao mau gerenciamento dos recursos e da política industrial do Governo para o Nordeste. Posicionavam-se contra o controle e o intervencionismo estatais na economia, e eram favoráveis à redemocratização do país e à implantação de um projeto liberal (Farias, 1997).

...[Este] grupo de empresários cearenses se apresentava à sociedade como portador de um "projeto civilizatório" para o Estado, na tentativa de imitar os filósofos do iluminismo, que tinham a tarefa, como se sabe, de ajudar a sociedade de sua época a alcançar a liberdade através do uso da razão. Arvorando-se da pretensäo de serem herdeiros do espirito iluminista, estes jovens empresários julgavam que [...] cabia a eles a tarefa de libertar a sociedade [cearense] das trevas, da "desrazão", do apadrinhamento e de fidelidade, estas últimas consideradas como sendo responsáveis por uma "mercantilização feudalesca" dos aparelhos de Estado. [...] mercantilização que 
impedia, sempre de acordo com eles, o uso racional da máquina estatal para implementar uma politica de desenvolvimento econômico-social. (Teixeira, 1995, p.3)

$\mathrm{Na}$ avaliação de Bonfim (1999), o CIC chamou a si a tarefa de resgatar os instrumentos estatais para a retomada do desenvolvimento econômico estadual, por meio da reforma das contas públicas e do modelo de gestão fiscal. Viabilizou a construção das salvaguardas financeiras que dariam lastro aos ambiciosos projetos de reconfiguração do capitalismo estadual. Para Bonfim, não condiz com a realidade a afirmativa de que o grupo chegou ao poder com tal propósito e a ele se dedicou desde o primeiro instante. Pelo contrário,

[...] a consciência da profundidade da ruptura a empreender e das possibilidades por ela abertas veio com o tempo, que forneceu as liçôes necessárias para o aprendizado sobre a organização da tarefa, em especial a de continuar vencendo eleições à medida que trilhava a senda da mudança. (Bonfim, Ibid., p.57)

Entretanto, para Farias (op. cit.), os jovens empresários tinham a consciência de que para realizar as mudanças preconizadas precisavam conquistar o poder institucional. No discurso de posse de Tasso Jereissati na terceira diretoria do CIC, em 1981, há uma passagem na qual fica claro o projeto de conquistar o poder: "o CIC tem um compromisso estadual, regional e nacional com a formação, o mais rápido possível, de uma classe política competente e forte, capaz de influenciar e até assumir o poder" (Farias, 1997, p.259).

Na mesma linha de raciocínio de Farias (Ibid.), Abu-el-Haj (1997) analisa que a atuação política da nova geração de empresários cearenses, em particular a geração do CIC, foi condicionada pela posição ocupada na produção e por suas relações com o Estado. E o método mais eficaz no seu processo de intervenção política foi através da conquista do cargo de governador estadual por Tasso Jereissati. O perfil destes empresários era, segundo este autor, baseado nos seguintes aspectos: engajamento em atividades industriais tradicionais de médio porte, e inserção em mercados complexos e de altos lucros.

O governo estadual adotou medidas para a interiorização do desenvolvimento, por meio de políticas diferenciadas de incentivo à localização do investimento industrial, trazendo aos municípios mais importantes do estado a oportunidade de empregar parte de seu contingente populacional em plantas industriais modernas, que não apenas se beneficiassem dos incentivos ofertados, mas também dos níveis salariais mais baixos e da pequena força da organização sindical nativa (Bonfim, 1999).

Farias (op.cit., p.274) destaca os projetos estruturais prioritários que, no segundo governo de Tasso Jereissati, tinham por objetivo fortalecer a economia do Ceará em longo prazo: a construção do Porto do Pecém, a internacionalização do aeroporto Pinto Martins, o Metrofor, os linhōes Banabuiú-Fortaleza e da CHESF (para ampliar a oferta de energia elétrica), a melhoria das rodovias estaduais, a interligação das bacias hidrográficas e a construção do açude Castanhão, além dos investimentos no setor turístico.

\section{A MODERNIZAÇÃO HÍdRICA DO “GOVERNO DAS MUDANÇAS"}

A atuação governamental no estado do Ceará no decorrer dos anos, na questão das águas, sempre foi predominantemente feita pelo governo federal, com o governo estadual 
40 Projeto Nordeste continha alguns projetos específicos, tais como o Programa de Apoio ao Pequeno Produtor Rural (PAPP/PDSFN), Programa de Irrigação Pública e Privada, Programa de Apoio às Micro e Pequenas Empresas no Interior, Programas de Educação Básica e Profissional do Meio Rural, Programas de Ações Básicas de Saúde no Meio Rural e Programa de Saneamento Básico no Meio Rural (Amaral Filho, 2003).

5 As informações referentes ao aparato estatal da Política de Recursos Hídricos são de Ceará (1995a).

60 SIGERH foi instituído pela Lei 11.196 de 24 de junho de 1992, complementado pela Lei 12.217 de 18 de novembro de 1993, que cria a Companhia de Gestão de Recursos Hídricos (COGERH), e pela Lei 12.245 de 30 de dezembro de 1993 , que dispõe sobre o Fundo Estadual dos Recursos Hidricos (FUNORH). A sua composição reúne um conjunto de órgãos colegiados de coordenação e participação, deliberação e execução da política estadual de recursos hídricos. Congrega instituições estaduais, federais e municipais, que, de algum modo, se relacionam com recursos hídricos e com aqueles representativos dos usuários de água e da sociedade civil. participando de forma muito tímida. Em conseqüência, acontecia uma inevitável dissociação entre os objetivos institucionais a as açóes propostas nos programas. O processo de planejamento era marcado pela quase total desarticulação dos órgãos envolvidos nos programas, desprovido de qualquer estratégia de ação integrada.

A implantação de uma nova política de recursos hídricos passou a fazer parte do pensamento estratégico do grupo que assumiu o poder no estado do Ceará em 1987, e foi incluída no conjunto das macro-reformas, ao lado da reforma do Estado e dos ajustes fiscal e financeiro. A partir daí, o governo estadual passou a implantar um ambicioso plano de oferta e disciplina do uso da água, tendo por base o argumento de que no passado não havia nenhuma preocupação, nem no estado nem na região, em se estabelecer uma estrutura capaz de ajudar a população das áreas rurais a lidar racionalmente com a escassez de água.

Segundo Amaral Filho (2003, p.15), no primeiro Plano de Governo de Tasso Jereissati (1987-1991), ainda não havia uma "idéia clara" do modelo de gestão de água para o estado, embora existisse a consciência da necessidade de se formular um modelo, orientado para o disciplinamento e a racionalização do uso dos recursos hídricos.

Considerando que as intervenções do governo contra os efeitos da seca eram emergenciais e de caráter assistencialista, com práticas de clientelismo, o Plano de Governo destacava que as soluções emergenciais deveriam ser abandonadas e deveriam ser estabelecidas soluções integradas, estruturais e permanentes (Ceará, 1987). Amaral Filho (op.cit.) destaca que o governo do estado depositou sua confiança na estratégia de desenvolvimento rural preconizada pelo Projeto Nordeste, ${ }^{4}$ que seria financiado pelos governos federal e estadual e pelo Banco Mundial.

No início de 1987 foram dados os primeiros passos na implantação da política estadual de recursos hídricos. Foi dado início ao estabelecimento de um aparato estatal ${ }^{5}$ e à implantação de políticas públicas para encaminhar a questão dos recursos hídricos, com destaque para a criação da Secretaria de Recursos Hídricos (SRH) - lei 11.306 de $1^{\circ}$ de abril de 1987 -, com a missão de promover o aproveitamento racional e integrado dos recursos hídricos do estado, coordenar, gerenciar e operacionalizar estudos, pesquisas, programas, projetos e serviços tocantes a recursos hídricos, e promover a articulação dos órgãos e entidades estaduais do setor com aqueles das instâncias federal e municipais.

Outras medidas institucionais foram: a criação da Superintendência de Obras Hidráulicas do Estado (SOHIDRA) - lei 11.380 de 15 de dezembro de 1987 -, com o objetivo de ser o braço técnico e executor das obras da Secretaria de Recursos Hídricos; a vinculação da Fundação Cearense de Meteorologia e Recursos Hídricos (Funceme) ao sistema de recursos hídricos. Desta forma, a SRH, a Funceme, a SOHIDRA e o Conselho de Recursos Hídricos passaram a compor o Sistema de Recursos Hídricos do Estado (Amaral Filho, 2003).

Uma das providências adotadas pela SRH foi a elaboração do Plano Estadual de Recursos Hídricos (PERH), que lançou as bases da política adotada pelo setor. O Plano propôs todo um aparato jurídico e institucional para o setor, além de promover a integração dos órgãos estaduais, federais e municipais, organizando-os no Sistema Integrado de Gestão de Recursos Hídricos (SIGERH). ${ }^{6}$

O Plano Estadual de Recursos Hídricos, que levou quatro anos para ficar pronto, constitui o mais importante estudo técnico consolidado já realizado no Ceará e pode ser considerado como a principal fonte arquitetônica do atual modelo estadual de gestão dos recursos hídricos (Amaral Filho, 2003).

Com a posse de Ciro Gomes em 1991, houve continuidade no processo de implantação do novo modelo de gestão de recursos hídricos, de forma a permitir a propagação dos 
desdobramentos do Plano Estadual de Recursos Hídricos, elaborado no governo de Tasso Jereissati (Id., Ibid.). O autor ressalta que, embora os princípios básicos da nova política já tivessem sido implementados pelo PERH, estes ainda não tinham penetrado no discurso político do novo governo.

A Política das Águas no Ceará, ${ }^{7}$ prevista no artigo 326 da Constituição Estadual, foi disciplinada pela Lei Estadual de Recursos Hídricos n. 11.996 de 24 de julho de 1996, e visa proporcionar os meios para que a água, recurso essencial ao desenvolvimento sócioeconômico, seja usada de forma racional e justa pelo conjunto da sociedade, em todo território do Ceará.

A Lei Estadual de Recursos Hídricos tem como objetivos: assegurar o desenvolvimento sustentado compatível com a oferta de água; assegurar a oferta de água em quantidade e qualidade para as geraçôes atuais e futuras; planejar e gerenciar, de forma integrada, descentralizada e participativa, o uso múltiplo, controle, conservação, proteção e preservação dos recursos hídricos.

A Política Estadual de Recursos Hídricos tem como elementos básicos: o Plano Estadual dos Recursos Hídricos, que contém um estudo detalhado da capacidade e das potencialidades dos recursos hídricos do estado do Ceará (este plano foi revisado em 2004); o Sistema Integrado dos Recursos Hídricos, em que os Comitês de Bacia, as Câmaras Técnicas e o Conselho de Recursos Hídricos do Estado do Ceará (CONERH), órgãos colegiados, definem e executam a Política Estadual de Recursos Hídricos; e o Fundo Estadual de Recursos Hídricos, criado em 1992 para dar suporte financeiro à Política Estadual de Recursos Hídricos, que conta com recursos de programas e projetos governamentais e com aqueles oriundos da cobrança pelo uso da água bruta.

A adoção da bacia hidrográfica ${ }^{8}$ como unidade de planejamento é um dos princípios fundamentais do gerenciamento dos recursos hídricos. O estado do Ceará foi dividido em onze bacias hidrográficas: Coreaú, Litoral, Curu, Metropolitana, Baixo Jaguaribe, Parnaíba, Acaraú, Banabuiú, Médio Jaguaribe, Alto Jaguaribe e Salgado (Amaral Filho, 2003).

As funções do Comitê de Bacia são permanentes e intermitentes, abrangendo desde o planejamento e acompanhamento da operação dos açudes estratégicos e principais sistemas hídricos até a negociação de tarifas pelo uso de água bruta. Também são atribuições do Comitê: acompanhar a implementação dos cadastros de usuários de água bruta, contribuir para a negociação de conflitos pelo uso da água em sua bacia, implementar campanhas educativas e participar do processo de elaboração dos Planos de Gerenciamento de Bacias.

Em 1993 foi criada a Companhia de Gestão dos Recursos Hídricos do Ceará $(\text { COGERH })^{9}$ (Amaral Filho, Ibid.), com a finalidade de gerenciar a oferta dos recursos hídricos constantes dos corpos d'água superficiais e subterrâneos de domínio do estado, e equacionar as questóes referentes ao seu aproveitamento e controle, operando, para tanto, de forma direta, por meio de subsidiária ou de pessoa jurídica de direito privado, mediante contrato, realizado sob forma remunerada.

Além da aprovação da Lei 11.996, de 24 de junho de 1992, que dispõe sobre a Política Estadual de Recursos Hídricos, Amaral Filho (2003) destaca mais três realizações do Governo Ciro Gomes: o aumento da capacidade de armazenamento e da oferta de água no Estado através da construção de açudes, barragens e canais; a realização de novas rodadas de estudos técnico-científicos que aconteceram no âmbito do Projeto Áridas, ${ }^{10}$ que contribuíram para ajudar a atualizar o Plano Estadual de Recursos Hídricos, ao mesmo tempo em que definiam os contornos da Política de Recursos Hídricos do Ceará; e o fe-
7 Os princípios, instrumentos, diretrizes e elementos da Política de Recursos Hídricos são de Ceará [s.d.].

8 Bacia hidrográfica é uma área onde toda chuva que cai, drena, por riachos e rios secundários, para um mesmo rio principal, localizado em um ponto mais baixo da paisagem, sendo separada das outras bacias por uma linha divisória denominada divisor de água.

9 A COGERH foi criada pela Lei $n^{\circ} 12.217$, de 18 de novembro de 1993, em conformidade com o artigo 326 da Constituição do Estado do Ceará como entidade da Administração Pública Indireta dotada de personalidade jurídica própria, organizada sob a forma de sociedade anônima, de capital autorizado.

100 Projeto Áridas foi uma reflexão realizada por equipes estaduais integradas dos estados do Nordeste, com a finalidade de repensar o desenvolvimento da região, tendo como referência o conceito de desenvolvimento sustentável. 0 Projeto Áridas nasceu na Fundação Esquel e teve o apoio da Secretaria de Planejamento, Orçamento e Coordenação da Presidência da República (SEPLAN/PR), além de cooperação técnica e institucional do Instituto Interamericano de Cooperação para a Agricultura (IICA). A idéia original deste projeto aconteceu na Conferência Internacional sobre Impactos de Variações Climáticas e Desenvolvimento Sustentável em Regiões Semi-Áridas (ICID), realizada em Fortaleza no início de 1992, como base preparatória para a Conferência Mundial de Desenvolvimento e Meio Ambiente (Eco-92) para assuntos relacionados ao Semi-Árido, desertificação e meio-ambiente (Amaral Filho, 2003). 
110 contrato 4531-BR para a implantação do PROGERIRH foi assinado com o Banco Mundial em 10 de fevereiro de 2000, com um valor total do projeto de US\$ 247,270,000.00; destes, o valor do contrato de financiamento do BIRD foi de US\$ $136,000,000.00$ e o valor da contra-partida, de US\$ $111,270,000.00$. Foi assinado também 0 contrato de $n^{\circ}$ 01.2.329.3.1 com o BNDES, em 30 de abril de 2002, para o financiamento de RS 126.000.000,00, divididos em dois subcréditos, o subcrédito $A$, de $R \$ 43.400 .000,00$, e subcrédito $B$, de $R S$ 82.600.000,00 (Ceará, 2005a). chamento de negociações com o Banco Mundial para obtenção de empréstimos para o financiamento do PROURB - Hídrico.

A parceria entre o estado e o Banco Mundial na questão das águas foi iniciada em 1994, com o financiamento do Projeto de Desenvolvimento Urbano e Gestão de Recursos Hídricos (PROURB), que teve como objetivos a consolidação do sistema estadual de gerenciamento de recursos hídricos, inclusive com a criação da COGERH, e o início da cobrança pelo uso desses recursos. O PROURB também implementou um ambicioso programa de construção de barragens e adutoras para o suprimento de água a diversas cidades do Estado.

Depois do início das obras do PROURB, o governo propôs ao Banco Mundial um programa de integração das bacias hidrográficas do Ceará, por meio da implantação do Programa de Gerenciamento e Integração dos Recursos Hídricos (PROGERIRH), que tem a concepção básica de transferência de recursos hídricos de zonas úmidas para zonas de escassez hídrica. O PROGERIRH foi criado pelo Governo do Estado em parceria com o Banco Mundial ${ }^{11}$ com o objetivo de promover a gestão eficiente e integrada dos recursos hídricos do estado do Ceará, mediante a racionalização do uso de água, o aumento de sua oferta para usos múltiplos, o incentivo à adequada gestão do solo e da vegetação nas bacias hidrográficas tributárias, a minimização de sua erosão, a construção de açudes estratégicos, a transposição de bacias, a criação de agrovilas e a irrigação ao longo dos eixos de transferência, com a abertura de novas fronteiras agrícolas, compondo assim, a Política de Recursos Hídricos do estado.

Amaral Filho (Ibid., p.29) destaca que o envolvimento do estado com o Banco Mundial foi importante, não somente pelo aporte financeiro, mas também:

[...] pela introdução do disciplinamento dos instrumentos, pelo aperfeiçoamento institucional, pela modernização dos procedimentos administrativos, pela mudança de mentalidade e também devido à melhoria da capacidade técnica dos recursos humanos envolvidos no sistema. Isto ocorrendo através da interação técnica, bem como através dos condicionantes econômico, financeiro, ambiental e social atrelados à concessão de empréstimos.

O segundo e terceiro governos de Tasso Jereissati continuaram a Política de Recursos Hídricos. O Plano de Governo do terceiro governo tomou como base as teses e propostas dos estudos do Projeto Áridas. Foram estes estudos, conforme afirma Amaral Filho (2003), que deram visibilidade à Política Estadual de Recursos Hídricos, dando contornos mais precisos ao modelo, inclusive agregando o conceito de desenvolvimento sustentável.

\section{A MODERNIZAÇÃO EXCLUDENTE DA BARRAGEM DO CASTANHÃO}

Nas seções anteriores, buscou-se explicar de que forma foi construído o "Ceará moderno" e como aconteceu a implantação da "modernidade hídrica" no estado, processos que estão imbricados com a construção da Barragem do Castanhão, que será analisada a partir dos pressupostos deste mesmo processo de modernização.

Duas grandes obras de infra-estrutura se destacam no projeto de desenvolvimento instaurado no estado do Ceará: o Complexo Industrial e Portuário do Pecém e o açude 
Castanhão. O Complexo Industrial e Portuário do Pecém foi concebido com o objetivo de dotar o estado do Ceará de um núcleo de irradiação de desenvolvimento. A Barragem do Castanhão, considerada um elemento central na política da gestão integrada das principais bacias e na política estadual de águas, visa superar a vulnerabilidade das atividades sociais e econômicas quanto à incerteza de disponibilidade de água, e induzir o uso eficiente da água, como bem econômico escasso (Ceará, [199-]).

Localizados na bacia hidrográfica do Jaguaribe, principal rio cearense, a barragem do Castanhão e seu reservatório estão situados nos municípios de Alto Santo, Jaguaribara, Jaguaretama e Jaguaribe. $\mathrm{O}$ vale do Rio Jaguaribe ocupa uma área de 72 mil quilômetros quadrados, ou a metade do território do Ceará. O Vale está situado em uma região semiárida e, em função do clima e da base geológica predominantemente cristalina, o regime dos rios é intermitente, fluindo apenas no período das chuvas. Até 1980, o Rio Jaguaribe era considerado o "maior rio seco do mundo", tendo sido perenizado com a construção do Açude Orós em 1960 e com a instalação de equipamentos hidráulicos em 1980.

Três vezes e meio maior que o açude Orós, o Castanhão tem capacidade para armazenar 6,7 bilhôes de $\mathrm{m}^{3}$ de água, com um volume útil de 4,211 bilhões na cota 100 e um volume morto de 250 milhões de $\mathrm{m}^{3}$ na cota 71 . O reservatório tem um comprimento máximo de $48 \mathrm{~km}$, área inundada de 32.500 hectares na cota 100 (cota de sangria), de operação normal, e 60.000 hectares na cota de cheia máxima.

A Barragem do Castanhão é considerada pelo Governo do Estado do Ceará como um projeto de uso múltiplo com forte componente de desenvolvimento regional, e representa fato de grande repercussão sócio-econômica no estado. A construção da Barragem do Castanhão foi apresentada como um importante meio de atender não apenas as necessidades de água da população do semi-árido, vítima de secas periódicas, mas também como um investimento estratégico de longo prazo capaz de oferecer múltiplos benefícios. A água, como um recurso territorial estratégico, tem se revelado elemento de fundamental importância para garantir a atração de indústrias para o estado, bem como para garantir o funcionamento do Complexo Industrial e Portuário do Pecém.

Com a finalidade de levar água para Fortaleza e região e para o Porto do Pecém, está sendo construído o Eixo de Integração Castanhão-Região Metropolitana de Fortaleza (RMF) pela SOHIDRA, ${ }^{12}$ com recursos do PROGERIRH: um sistema de adução, com $255 \mathrm{~km}$ de comprimento, composto por uma estação de bombeamento, 166,59 km de canais, 93,0 km de adutoras e 1,1 km de túneis. A obra permitirá a transposição do açude Castanhão para reforçar o abastecimento da Região Metropolitana de Fortaleza e também do Complexo Industrial e Portuário do Pecém, fazendo a integração das bacias hidrográficas do Jaguaribe e da Região Metropolitana. ${ }^{13}$ Este empreendimento é considerado fundamental para o suprimento, com garantia adequada, das demandas hídricas da Região Metropolitana de Fortaleza, incluindo o Complexo Industrial e Portuário do Pecém.

Os primeiros estudos topográficos e geológicos sobre a Barragem do Castanhão datam de 1910. De acordo com Tavares (2004), o geólogo americano Roderic Crandall, consultor do Serviço de Geologia e Mineralogia do Brasil, descobriu o Boqueirão do Cunha, hoje situado no município de Alto Santo, na aproximação do chamado Baixo Vale do Rio Jaguaribe, ao estudar seções naquele rio que poderiam ser fechadas para o armazenamento d'água, como forma de regularizar a oferta deste recurso, em um território regido pelas irregularidades climáticas e constituído, em quase toda sua totalidade, de solos rasos de geologia cristalina.
12 Informações disponiveis em: http://www.sohidra.ce. gov.br.

130 primeiro trecho do Eixo de Transposição foi inaugurado em dezembro de 2004. 
Conforme Tavares (Ibid.), a descoberta não foi tão festejada na época, pois o relatório de Crandall adiantou que o sítio barrável em questão seria mais adequado à construção de uma barragem de pequeno porte, para derivação das águas para futuros canais de irrigação, pois se situava no limite extremo sul das manchas irrigáveis do baixo Jaguaribe. Apenas em meados de 1955, a construção do eixo barrável foi cogitada, quando se apresentou como alternativa à barragem do Orós, sendo preterido por esta última, que teve as obras iniciadas e concluídas ainda no Governo Juscelino Kubitscheck.

A partir do início dos anos 1980, a Barragem do Boqueirão do Cunha, atualmente Barragem Castanhão, passou então a ser estudada, agora pelo Departamento Nacional de Obras de Saneamento (DNOS), no âmbito dos estudos de transposição das águas do São Francisco para o Nordeste Semi-Árido, com a finalidade de desempenhar o papel de reservatório pulmão (Tavares, Ibid.). Em setembro de 1987 foi contratado o Consórcio Hidroservice/Noronha pelo DNOS, para elaboração dos Estudos Básicos, Anteprojeto, Projeto Básico e Projeto Executivo (Araújo, 1997).

Com a extinção do DNOS, seu patrimônio e competências foram transferidos para o DNOCS, inclusive o futuro empreendimento Barragem do Castanhão. Desta forma, o Projeto do Castanhão só chegou ao conhecimento do DNOCS em dezembro de 1986 (Tavares, Ibid.).

Em 1989, o DNOCS iniciou a contratação do Relatório de Impacto Ambiental (RIMA), o cadastramento das terras e benfeitorias, e o remanejamento da população atingida. O Projeto Básico, devidamente aprovado, serviu de suporte para efetivação da Concorrência Pública no 08/89-DGO/G, realizada em dezembro de 1989. A vencedora da licitação foi a Construtora Andrade Gutierrez S.A., porém, o resultado esteve "sub-judice" por quase dois anos, em função de recursos interpostos por empresa concorrente. Em outubro de 1991, o Supremo Tribunal de Justiça deu provimento a recurso interposto pela Construtora Andrade Gutierrez, encerrando assim o processo licitatório, dando ganho de causa à empresa que apresentou o menor preço (Araújo, op. cit.).

As obras de construção da Barragem do Castanhãa ${ }^{14}$ foram contratadas pelo DNOCS

14 Em julho de 1995, 0 DNOCS celebrou um Convênio com o Governo do Estado do Ceará, a fim de viabilizar as ações decorrentes da Construção da Barragem do Castanhão, no que se refere ao envolvimento com populações, como a construção da cidade de Nova Jaguaribara e o Reassentamento da População Rural, bem como outras ações pertinentes à execução da obra. Em 22 de outubro de 1996, o DNOCS assinou o Contrato $n^{\circ}$ PGE 16/96 com o Consórcio Aguasolos/Hidroterra, vencedor da licitação para Execução de Serviços de Consultoria para Acompanhamento, Assessoria e Fiscalização das Obras da Barragem do Castanhão. (Araújo, op. cit). em 05 de dezembro de 1991, através do Contrato no PGE 01/91, com a Construtora Andrade Gutierrez S.A., porém, a 1a Ordem de Serviço só foi emitida em 16 de novembro de 1995.

Desde que o DNOS lançou a idéia e projetou a construção do Castanhão, com o conseqüente aparecimento das notícias de sua construção em 1985, o Castanhão se constituiu em uma obra polêmica, cercada de imensos questionamentos. As divergências técnicas foram o principal elemento desencadeador da polêmica em torno da obra (Silveira, 2000). Um dos líderes dessa oposição técnica foi o engenheiro civil Manfredo Cássio de Aguiar Borges, que foi por mais de vinte anos chefe da Divisão de Hidrologia do DNOCS. Borges dirigiu suas críticas aos erros do dimensionamento hidráulico do reservatório; aos erros e conseqüências da concentração de água no terço inferior do Vale do Jaguaribe; e aos erros e consequiências da implantação de um lago com superfície extremamente grande para uma região seca e quente, o que ocasionaria uma grande perda de água por evaporação.

Igualmente foi objeto de críticas a "dança" dos objetivos e benefícios advindos da Barragem. Críticas estas que foram bastante consistentes, uma vez que os objetivos dessa obra sempre variaram ao sabor do contexto da época, dos projetos e das conveniências governamentais, bem de conformidade com o que uma barragem de "usos múltiplos" pode oferecer. Exemplo muito claro disso pode ser percebido quando se constata a importância da 
Barragem do Castanhão para o Complexo Industrial e Portuário do Pecém, e de como, uma Barragem que agora é considerada o coração da política de águas do estado, não recebeu a mesma qualificação quando da elaboração do Plano Estadual de Recursos Hídricos.

Esta "dança" de objetivos também é citada por Bernadete Neves, freira que liderou a organização da comunidade de Jaguaribara frente à construção da barragem do Castanhão:

Os objetivos da barragem sempre foram apresentados de acordo com o contexto da época. Sabemos que o projeto teve origem nos gabinetes do DNOS, no Rio de Janeiro, fora da realidade do Semi-Árido. De inicio, eles apresentavam dois objetivos: um era a irrigação da Chapada do Apodi, e o outro era a transposição do São Francisco. Em 1985 houve muitas enchentes, então eles aproveitaram para dizer que o projeto iria atenuar o nivel de enchentes no Vale. Diziam mesmo que acabaria com as enchentes. Numa outra época, o projeto passou a ter como objetivo a geração de energia. Eles vão mudando os objetivos de acordo com os interesses do momento. [...] Eles vão manipulando, vão fazendo os objetivos de acordo com o contexto da época, para conseguirem a aprovação do povo. Durante um ano de seca, um outro objetivo foi levar água para Fortaleza. Agora é a transposição do São Francisco. O que sentimos é que isto faz parte de um plano maior, de favorecimento de empreiteiras. (IMOPEC, 1999, p.26)

A população de Jaguaribara, cidade que foi submersa pelas obras da Barragem, ${ }^{15}$ teve um papel fundamental na discussão que se estabeleceu em torno de sua construção, embora, segundo os próprios moradores, não se possa dizer que o povo de Jaguaribara tenha se organizado em decorrência da construção da barragem. Quando a notícia da barragem chegou, já há seis anos se desenvolvia a discussão, organização e formação de lideranças, com forte presença da Igreja Católica, em particular de Irmã Bernadete. A população utilizou todas as estratégias disponíveis para impedir a realização da obra. Quando se constatou a inevitabilidade do projeto, surgiram as discussóes de compensações sociais, econômicas e financeiras à população urbana e rural.

Uma questão muito importante a ser resolvida dizia respeito ao desejo da população de ficar nas margens do rio, em vez de ser deslocada para assentamentos de reforma agrária em outras localidades. Para muitos, isso seria uma violência à tradição deles. Jaguaribara era um lugar com uma tradição cultural que deveria ter sido preservada. Desde que a Confederação do Equador teve o desfecho na região e o corpo de Tristão Gonçalves teria sido sepultado na igreja local, Jaguaribara passou a fazer parte do mapa histórico do Ceará. ${ }^{16}$ A praça principal da cidade tinha o nome de Tristão Gonçalves. Existia um marco que era muito visitado e, particularmente no dia 31 de outubro, o marco era alvo de visitas por alunos das escolas locais.

O desrespeito aos critérios estabelecidos para as indenizaçōes (justa, prévia e em dinheiro) criou problemas para as pessoas que compraram propriedades nos municípios vizinhos confiando nelas, pois tiveram que devolver as terras porque não puderam consolidar a compra devido a atrasos nos processos de indenização.

Outro problema grave dizia respeito ao descompasso muito grande entre o ritmo das obras da barragem e o da construção da nova cidade e, principalmente da formação dos assentamentos rurais. Para muitos, o pagamento das indenizações e o citado descompasso constituíram um dos problemas mais sérios.

Com a transferência para a nova cidade sendo anunciada pelo Governo do Estado, persistia a disputa e a negociação entre Governo e comunidade, conforme mostra Nascimento (2003, p.21), ao mencionar a produção de uma série especial de matérias veicula-

\begin{abstract}
15 Embora Jaguaribara tenha sido o município mais atingido, as obras de construção da Barragem atingiram também Jaguaretama, Alto Santo e Morada-Nova, os quais cederam parte de seus territórios para o novo município de Jaguaribara. Jaguaretama ainda teve parte de seu território atingido pelas obras.
\end{abstract}

16 Escavações feitas na Igreja Santa Rosa de Lima, quando da demolição da cidade de Jaguaribara, não localizaram os restos mortais de Tristão Gonçalves. (Diário do Nordeste, 15 de outubro de 2001). 
17 Informação constante nos Planos de Reassentamento do IDACE. das no Programa "No Ceará é assim" da TV Jangadeiro, emissora de propriedade de Tasso Jereissati, sobre a transferência dos moradores e a estrutura da nova sede.

Segundo a autora, tais matérias difundiam os benefícios de uma cidade planejada, "nascida do processo democrático", na qual "seu planejamento, desde a sua localização até a estrutura física urbana, contou com a participação da população" - conforme Informativo da Secretaria do Desenvolvimento Urbano e Meio Ambiente do Governo do Estado do Ceará -, embora não se constituíssem em fonte isenta, dado que não havia espaço nestas mesmas matérias para a divulgação das idéias contrárias ao Governo. Enquanto isso, a comunidade, com apoio de algumas entidades, produzia e divulgava material declarando sua posição divergente no processo.

A transferência dos moradores para Nova Jaguaribara teve início em 2000. Em 2002, a nova cidade, distante $55 \mathrm{~km}$ da antiga sede, foi inaugurada pelo Governo do Estado. Nova Jaguaribara possui área territorial de $595,60 \mathrm{~km}^{2}$ e passou a ter como limites o município de Morada Nova, ao norte; os municípios de Alto Santo e Iracema, a leste; o município de Jaguaribe, ao sul e o município de Jaguaretama, a oeste (Ceará, 1995b).

Segundo Pontes (2004), as recomendações relativas ao reassentamento estavam ligadas essencialmente à população urbana, em função de exemplos negativos que já haviam ocorrido em outras obras no Brasil e, também devido à organização da população urbana de Jaguaribara. A área rural não se constituía em motivo de preocupação, dada a dispersão da população e a ausência de resistência e organização. Eles não estavam incluídos nos planos de modernidade.

A construção da Barragem Castanhão deslocou compulsoriamente uma população de 2.268 famílias no meio rural, em área circunscrita ao futuro lago, até a cota 110. Destas famílias, 1.515 foram consideradas reassentáveis, uma vez que não tinham condições de se restabelecer por sua própria conta, por serem simples moradores ou porque, sendo proprietários, receberam uma indenização que não lhes permitia se restabelecer dignamente (Ceará, 2004). ${ }^{17}$

O Governo do Estado, vislumbrando a magnitude das ações do reassentamento e não possuindo recursos para o cumprimento do convênio que tratava da execução de ações referentes à barragem do Castanhão, solicitou uma alteração no mesmo, através de aditivo. No momento da rediscussão das competências e valores, coube ao DNOCS a responsabilidade pelo reassentamento rural, inicialmente com o Governo do Estado, e este, como contrapartida, construiria a nova sede de Jaguaribara. O DNOCS repassaria os recursos necessários ao Instituto de Desenvolvimento Agrário do Ceará (IDACE), que seria o executor do reassentamento rural (Pontes, $o p$. cit.)

Não havia uma idéia de movimento de atingidos na região até os anos 1990. A história do Movimento dos Atingidos por Barragens (MAB) no Castanhão, enquanto movimento organizado de luta contra barragens, se iniciou a partir de 1993, especialmente quando um dos atuais líderes do movimento começou a participar das reuniões que aconteciam em Jaguaribara, Fortaleza e São Paulo, em 1997. A idéia do movimento começou a tomar forma a partir da insatisfação quanto ao modo como a questão da barragem estava sendo tratada pelas lideranças de Jaguaribara. Hoje, o MAB tem destacada atuação no enfrentamento dos problemas advindos da implantação da Barragem.

A liderança exercida pela freira Bernadete Neves provocou, por volta de 1999/2000 vários confrontos internos, com discordâncias quanto à maneira como o trabalho estava sendo conduzido, principalmente no enfrentamento com o governo, estabelecendo-se uma clara disputa entre a Igreja, na pessoa da Irmá Bernadete, e o MAB. 
A falta de planejamento do Estado para o equacionamento dos problemas dos atingidos no meio rural foi outro fato que contribuiu para a organização do MAB na região, que veio dar maior visibilidade a estas questôes, organizando manifestações, encaminhando documentos, conseguindo meios para resolver emergencialmente a situação de penúria em que se encontrava a maioria dos atingidos, e buscando uma interlocução direta com os órgãos envolvidos, principalmente com o DNOCS.

O reassentamento dos atingidos do meio rural, com a multiplicidade de órgãos estatais envolvidos, esteve cercado de problemas, desde o início; o desenvolvimento ou modernização pretendido com a implantação da Barragem passou ao largo do processo descrito por Cernea e McDowell (2000), que tem em vista elevar o padrão de vida, saúde, alfabetização, reduzir a pobreza e fortalecer o meio ambiente.

Se os componentes fundamentais que devem ser considerados nos processos de deslocamento, a fim de se alcançar o desenvolvimento, são a ausência de pessoas sem terra e sem teto, desempregadas, marginalizadas, sofrendo de insegurança alimentar, com falta de acesso aos recursos comunitários e sem desarticulação dos laços comunitários, o modelo de desenvolvimento e de modernização posto em prática no Castanhão realmente falhou nesse sentido.

É se é possível também, como advogam Cernea e McDowell (Ibid.), que, sob políticas claras, podem ser protegidas mais efetivamente as práticas que constituem os direitos civis, dignidade humana e os direitos econômicos dos que são sujeitos à realocação involuntária, constata-se que faltou no Castanhão uma política clara para o reassentamento rural. Se nessa perspectiva, reassentamento e restabelecimento das condições de vida são domínios nos quais se afirmam os direitos humanos, estendendo a justiça social e promovendo a inclusão em vez de exclusão proeminente nas agendas políticas, pode-se afirmar que aconteceu no Castanhão um processo de modernização excludente.

Se tomarmos como base as recomendações da Comissão Mundial de Barragens, fundadas nos valores de equidade, sustentabilidade, eficiência, processo decisório participativo e responsabilidade, a situação dos atingidos pode ser considerada ainda mais excludente.

Sem dúvida, foi um avanço a instalação do Grupo de Trabalho Multiparticipativo para Acompanhamento das obras da Barragem do Castanhão, instância criada pelo Governo do Estado com o objetivo de discutir as ações relacionadas à Barragem do Castanhão e para servir como um fórum de debates acerca dos problemas oriundos de sua construção. Em que pese a inovação da medida, diferente das adotadas até então na construção de grandes obras de infra-estrutura, o Grupo Multiparticipativo funcionou muito mais no sentido de legitimação das ações governamentais do que como fórum efetivo de participação da sociedade civil. Isto se verifica fundamentalmente em seu funcionamento. Afinal, a participação democrática da sociedade efetivamente não ocorreu, se for considerado que a participação não se restringe a expor os problemas, mas em ter a possibilidade de influir nos resultados.

Como pode ser considerado democrático um fórum para tratar das questões referentes à construção de uma grande obra, se é fechada a porta à participação formal de um movimento de representação dos atingidos por ela? O convite formal para a participação do MAB no referido Grupo só ocorreu quando não havia mais o que ser decidido e quando os movimentos sociais passaram a ter mais visibilidade. Como se pode dizer que a população participou efetivamente, se só podia decidir questóes que não implicassem em realocação dos recursos, que foram prioritariamente dirigidos para a obra da barragem e da construção da nova cidade? 
No que tange à participação da comunidade tão propagada pelo Governo do Estado, cabe uma reflexão particular acerca da ação desenvolvida pelo Instituto de Desenvolvimento Agrário do Ceará (IDACE), representante do governo estadual no processo de reassentamento. O trabalho do IDACE teve por base uma metodologia participativa que já vinha sendo utilizada em assentamentos de reforma agrária no Ceará, mas que se mostrou problemática no caso da Barragem do Castanhão, dado o pouco poder de decisão que tinham seus técnicos no processo de reassentamento e à forma como se processou o reassentamento rural, sempre a reboque dos outros processos.

A modernização pretendida pelo governo das "mudanças" apresentou, pelo menos no discurso, todos os aspectos relacionados por Gomes (2000) como indicativos do moderno: o caráter de ruptura, a imposição do novo e a pretensão de alcançar a totalidade. Como o mecanismo de substituição do antigo pelo novo é a ruptura, a necessidade imperiosa de ruptura com os "coronéis" fazia parte da afirmação de sua modernidade pretendida. Conforme Heller e Feher (1994), a instituição existente é atacada do ponto de vista de um imaginário (futuro), sendo transformada em instituição velha. Assim, todos os que se posicionaram contra o "novo" que estava sendo implantado no Ceará, também passaram a ser considerados como "forças do atraso", numa pretensão clara de alcançar a totalidade.

Outro aspecto a ser considerado na modernização do governo das "mudanças" diz respeito ao que Touraine (2002) chama de concepção ocidental da modernidade, em que a racionalização era a própria razão e a necessidade histórica que preparava seu triunfo. Desta forma, a racionalização se torna um aspecto essencial da modernidade e um mecanismo necessário para realizar a modernização. Neste aspecto, as ações do governo das "mudanças” se revestiram de um caráter técnico-racional sem precedentes na história do Ceará.

Se a modernização pode ser entendida como o desenvolvimento da racionalidade instrumental e representa o marco econômico e cultural de nossa época, sendo um critério necessário ao desenvolvimento econômico e estabelecendo o referencial obrigatório para qualquer política, conforme Lechner (1990), o processo de uso e controle das águas no Ceará certamente tem contribuído para levar o estado a se transformar num paradigma da "modernização hídrica", pensada nos seus aspectos puramente técnicos, citada como exemplo a ser seguido por outros estados do país.

Entretanto, a modernização das práticas de planejamento e gestão de recursos hídricos em escala estadual se concretiza através de práticas tradicionais. Na verdade, seria mais justo dizer, no caso do Castanhão, que se assiste a uma combinação híbrida de formas modernas, planejadas e abertas, mesmo que de maneira incompleta à participação, com fortes traços de exclusão política, em que o social ainda é moeda de troca.

Isto pode ser percebido muito claramente na questão do valor teto das indenizaçôes - que determinava quem teria direito ao reassentamento -, apenas apresentado e não discutido com os atingidos, que não tiveram qualquer ingerência na definição deste valor, restando apenas a aceitação, ou a migração, como aconteceu com um número razoável de famílias. Isto também é verificado quando se compara o número de reassentáveis nos planos iniciais de reassentamento e os dados mais recentes de famílias reassentadas.

A participação "adjetiva" que os atingidos tinham no Grupo Multiparticipativo, quando se tratava de resolver as questôes mais importantes, e que diziam respeito às verbas, certamente não pode ser configurada como inclusão. E o tratamento dispensado ao $\mathrm{MAB}$ não poderia ser caracterizado como exclusão política? No Castanhão, as dimensões sociais do processo de modernização fracassam em um modelo que não consegue incorporar importantes segmentos sociais. 


\section{CONSIDERAÇÕES FINAIS}

A análise permite constatar que o processo de uso e controle das águas no Ceará, tendo como base o processo de construção da Barragem do Castanhão, colocou o estado como exemplo a ser seguido, e contribuiu para levá-lo a se transformar em um modelo de modernização, no que diz respeito a "modernização hídrica". Se pensarmos em todo o aparato técnico e no desenvolvimento institucional, certamente houve modernização; entretanto, esta modernização ocorreu em detrimento de interesses e direitos de setores sociais que continuam estruturalmente à margem do mercado e à margem da proteção estatal, pois a modernidade hídrica implantada no Ceará buscou transformar o espaço geográfico no espaço da racionalidade técnica a serviço de interesses privados.

$\mathrm{O}$ aparato institucional criado para dar corpo à modernização hídrica foi funcional para a concretização deste projeto de modernidade, inclusive com o envolvimento do Estado com o Banco Mundial, que propiciou a introdução do disciplinamento dos instrumentos, conseguidos através do aperfeiçoamento institucional e da modernização dos procedimentos administrativos. Isto ocorreu não apenas pela interação técnica, mas também por meio dos condicionantes atrelados à concessão de empréstimos.

O Ceará, como cliente do Banco Mundial, se empenhou em desenvolver leis, regulamentos e instituições requeridas para administrar os recursos hídricos de maneira mais economicamente produtiva, socialmente aceitável e ambientalmente sustentável e, a exemplo dos demais prestatários do Banco Mundial, também precisou desenvolver e manter uma ação apropriada de infra-estrutura de água.

Entretanto, a institucionalização posta em prática nas questôes ligadas diretamente ao reassentamento da população rural afigurou-se como um elemento complicador do processo, tendo gerado interferências e conflitos entre os diversos níveis e instâncias, tanto governamentais, como com a Igreja, o MAB e representantes da comunidade.

Não restam dúvidas quanto à necessidade de uma adequada gestão dos recursos hídricos em um estado que sempre sofreu em decorrência das irregularidades climáticas. Resta esperar que os benefícios desta pretensão de modernidade não fiquem concentrados nas mãos de poucos e se convertam em benefícios sociais que irão melhorar a vida da população, ou ao menos, formular um novo conceito que reinvente o progresso.

$\mathrm{Na}$ época em que imperavam os interesses clientelistas, a implantação de indústrias era apresentada como solução para libertar a população nordestina dos efeitos da seca. E foi no esteio deste discurso que o grupo urbano-industrial que governou o Ceará nas duas últimas décadas se formou, ou pelo menos se fortaleceu, se beneficiando dos incentivos fiscais da Sudene, com o aval dos "coronéis" da política cearense.

A seca continua sendo usada, não mais pela "indústria da seca", mas como justificativa para a acumulação de água para beneficiar a indústria, de acordo com a visão empresarial dada à água; os interesses clientelistas da época dos "coronéis" no uso e controle da água, expressos pela construção de açudes e poços em propriedades particulares e outros expedientes que ficaram marcados no imaginário popular como a "indústria da seca”, se transformaram em interesses dos "industriais da seca" para atender a uma burguesia urbano-industrial. A implantação de indústrias (ou agroindústrias) continua sendo a resposta para o desenvolvimento, mas desta vez ancorada pela implantação de mega projetos hídricos associados à modernidade.

Os cearenses deverão agora se acostumar a olhar para o solo, redesenhado pelo "caminho das águas", na esperança de que a modernização promovida deixe de ser excluden- 
Francisca Silvania de Sousa Monte é doutora em Planejamento Urbano e Regional -IPPUR/UFRJ e professora adjunta da Universidade Federal do Ceará. E-mail: silvaniamonte@uol.com.br

Artigo recebido em agosto de 2008 e aprovado para publicação em janeiro de 2009. te e contemple todos aqueles que durante séculos se acostumaram a olhar para o céu, na esperança de chuva, especialmente a população do meio rural, a mais atingida pelas irregularidades climáticas.

Além dos processos de exclusão econômica que são a marca do capitalismo na periferia (e aqui estamos falando de periferia da periferia), o processo político e social foi engendrado e engendrou sua modernização de forma incompleta ou truncada no processo de construção da Barragem do Castanhão. Será este o destino da modernização tropical?

\section{REFERÊNCIAS BIBLIOGRÁFICAS}

ABU-EL-HAJ, J. "Neodesenvolvimentismo no Ceará: autonomia empresarial e politica industrial". Revista Econômica do Nordeste, Fortaleza, v.28, n.3, pp.327-45, jul./set.1997. AMARAL FILHO, J. do. Reformas estruturais e economia politica dos recursos hidricos. Texto para discussão n.7. Fortaleza: IPECE, 2003.

ARAGÃO, R. B. História do Ceará. 2a. ed. Fortaleza: Ed. do Autor, 1998.

ARAÚJO, M. Z. T. de. Barragem do Castanhão: projeto e aspectos da construção. Fortaleza: Departamento Nacional de Obras contra as Secas, 1997.

BARREIRA, Y. A. F. "Ideologia e gênero na política: estratégias de identificação em torno de uma experiência”. Dados, Rio de Janeiro, v.36, n.3, p.441-468, 1993.

"Pensamento, palavras e obras". p. 63-82. In: PARENTE, J.; ARRUDA, J.

M. (Org). A era Jereissati: modernidade e mito. Fortaleza: Fundação Demócrito Rocha, 2002.

BONFIM, W. L. de S. Qual mudança?: os empresários e a americanização do Ceará. 1999. 295p. Tese (Doutorado em Ciências Humanas: Ciências Políticas). Instituto Universitário de Pesquisas do Rio de Janeiro, Rio de Janeiro, 1999.

CARVALHO, R. V. A. "Coronelismo e neocoronelismo: eternização do quadro de análise política do Nordeste?”. Revista Cadernos de Estudos Sociais. v.3, n.2, jul./dez.1987, p.193-205.

CEARÁ. Águas do Ceará: programa de gerenciamento e integração dos recursos hídricos do Estado do Ceará. Fortaleza: Secretaria de Recursos Hídricos, 1995a. Emenda Constitucional no 25/95, de 22 de dezembro de 1995b.

. Nota acerca da contribuição da Barragem do Castanhão para o desenvolvimen-

to sustentável do Ceará. Fortaleza: Secretaria de Recursos Hídricos, [199-]. Plano de mudanças do governo Tasso Jereissati (1987-1991). Fortaleza, Governo do Estado, 1987.

Plano de desenvolvimento sustentável do governo Tasso Jereissati (1995-1998).

Fortaleza, Governo do Estado, 1995c.

Companhia de Gestão de Recursos Hídricos. O caminho das águas. [s.d] Disponível em <http://www.cogerh.ce.gov.br>. Acesso em 12 jul.2003.

Instituto de Desenvolvimento Agrário do Estado do Ceará. Documentos produzidos entre 1986 a 2004 (40 Planos de Reassentamento dos Núcleos, Cadastro dos atingidos pela Barragem do Castanhão e Planos de Desenvolvidos dos Reassentamentos do Castanhão). Fortaleza, [2004?].

. Secretaria de Recursos Hídricos. Progerirh: programa de gerenciamento e integração dos recursos hídricos. Relatório de execução (jan. a mar. 2005) Tomo I. No 01/2005.Fortaleza: SRH, 2005.a 
Progerirh: programa de gerenciamento e integração dos recursos hídricos. Relatório de execução. (jan. a mar. 2005) Tomo II. n. 01/2005. Fortaleza: SRH, 2005.b

CERNEA, M.; MCDOWELL, C. Risks and reconstruction: experiences of resettlers and refugees. Washington, DC: World Bank, 2000.

DIÓGENES, G. "Ciro Gomes: percursos de uma imagem". In: PARENTE, J.; ARRUDA, J. M. (Org.). A era Jereissati: modernidade e mito. Fortaleza: Ediçōes Demócrito Rocha, 2002.

FARIAS, A. de. História do Ceará: dos índios à geração Cambeba. Fortaleza: Tropical, 1997

GOMES, P. C. da C. Geografia e modernidade. Rio de Janeiro: Bertrand Brasil, 2000.

GONDIM. L. M. P. “Os 'governos das mudanças' (1987-1994)”. In: SOUSA, S. (Org.) Uma nova história do Ceará. 2a.ed. Fortaleza: Ediçōes Demócrito Rocha, 2002.

HELLER, A.; FEHÉR, F. "O pêndulo da modernidade". Tempo social. Rev. Sociol. USP, São Paulo, v.6, n.1-2, p.47- 82, 1994.

INSTITUTO DE MEMÓRIA DO POVO CEARENSE. Jaguaribara, resistindo e vivendo. Fortaleza: IMOPEC, 1999.

LECHNER, N. "A modernidade e a modernização são compatíveis? O desafio da democracia latino-americana”. Lua Nova. São Paulo, n.21, p. 73-86, set.1990.

LEMENHE, M. A. "A 'modernidade' ao alcance de todos". In: BARREIRA, Y.; PALMEIRA, M. (orgs.) Candidatos e candidaturas: enredos de campanha eleitoral no Brasil. São Paulo: Annablume, 1998.

LINHARES, M. Virgílio Távora: sua época. Fortaleza: Casa de José de Alencar, 1996.

MAGALHĀES, C. C. O desenvolvimento do Nordeste e a ação do BNB. Fortaleza: BNB, 1979.

MATOS, F. J. L.; ALCÂNTARA, S. V. S.; DUMMAR, V. C. (Coord.) Cenários de uma politica contemporânea. Fortaleza: Edições Fundação Demócrito Rocha, 1999.

NASCIMENTO, M. A. G. do. Nem parece o tempo em que vocês jogavam biriba na calçada: o lugar em Nova Jaguaribara. 2003. 144p. Dissertação (Mestrado em Geografia). Universidade Estadual do Ceará, Fortaleza, 2003.

PARENTE, F. J. C. A fé e a razão na politica: conservadorismo e modernidade das elites cearenses. Fortaleza: Edições Universidade Federal do Ceará, 2000. "O Ceará e a modernidade". In: PARENTE, J.; ARRUDA, J. M.

(Org). A era Jereissati: modernidade e mito. Fortaleza: Fundação Demócrito Rocha, 2002.

PONTES, R. C. B. V. Reassentamento involuntário de populaçôes atingidas pela construção de obras de infra-estrutura hídrica: o caso da Barragem do Castanhão, no estado do Ceará. Trabalho de investigação apresentado à Universidade de Barcelona como parte das exigências do Curso de Doutorado em Planificação Territorial e Desenvolvimento Regional. Barcelona, 2004.

SILVEIRA, E. M. da. Naufrágio de uma saudade: história da resistência da população da cidade de Jaguaribara à sua submersão, pela construção da Barragem do Castanhão. 2000. 164p. Dissertação (Mestrado em História). Faculdade de História, Direito e Serviço Social. Universidade Estadual Paulista "Júlio de Mesquita Filho", Campus de Franca, Franca, 2000.

TAVARES, C. A. “Castanhão: esperança ou dívida social". Revista Conviver Nordeste. Fortaleza, n.2, p. 62-65, 2004. 


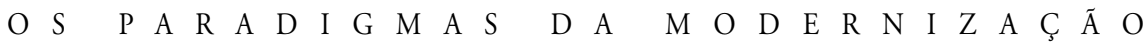

TEIXEIRA, F. J. S. “CIC: a 'razão esclarecida' da FIEC”. Propostas alternativas. Fortaleza, n.4, 1995.

TOURAINE, A. Critica da modernidade. 7.ed. Petrópolis: Vozes, 2002.

A B S T R A C T This study is part of a doctorate thesis that investigated how the process of use and control of water supply in Ceará State from the Castanhão Dam contributed to transform the state in paradigm of modernization, particularly water resources modernization. Politicians, government agents, social organizations, and other relevant agents involved in the process, were interviewed. Many documents and reports from several institutions involved in the dam construction were also analyzed. It was concluded that water resources modernization is drawing a new territorial configuration in the Ceara State, transforming the geographic space in a space of technical rationality to serve private interest, and that the development intended with the dam construction resulted in a process of excluding modernization mainly to those directly affected by the dam.

K E Y W O R D S Modernization, Development, Ceará, Dam, Water, Exclusion. 